\title{
Contributions Toward a Theory of Regulation.
}

\section{The Significance of the Different Methods of Regulation in Turbellaria.}

By

\author{
C. M. Child. \\ With 65 figures in text. \\ Eingegangen am 7. August 1905.
}

\section{Introduction.}

The genus Planaria has long been known as possessing a remarkable degree of regulatory power. A great mass of experimental data regarding this form has accumulated which in later years has been supplemented by work upon related forms.

Thus far, however, work has been confined very largely to a description of the facts of regulation rather than interpretation and unification of the data. Driesch, it is true, has been forced by his own experiments along this line to the conclusion that the vital processes follow other laws than those of chemistry and physies, but his views have not, thus far, met with general acceptance.

My own experiments during the last five year's have naturally led me to formulate more or less definite conclusions regarding the phenomena observed, some of which have already been stated in my »Studies on Regulation" (CHrd, '02-'05).

Experiments on polyclads and rhabdocoels form the basis for the ideas expressed in these papers but numerous experiments of my own upon the triclads and examination of the great mass of data already accumulated by others have convinced me that the facts are quite sufficient not only to warrant but to demand further attempts at interpretation and arrangement. Morgax and his students as well as others have given us a remarkable array of facts but the general conclusions are few. Except as concerns the relation between 
regeneration and adaptation MORGAN's conclusions refer chiefly to particular cases and no general foundation for the interpretation of the many facts is established. Personally, I am inclined to believe that the phenomena of regulation afford us a deeper insight into the nature of processes concerned with the development of form and structure than any other field of investigation at present available. And as we become able in future to control these phenomena more fully and modify them experimentally a more complete analysis will be possible and more fundamental conclusions can be attained. It is perhaps needless to emphasize the fact that the results from this field must possess great significance in the general problems of biology.

But without making any unduly ambitious attempt at solution of the problems involved I desire simply to bring together certain facts some of which have already been discussed, and to show how readily they fall into line and permit interpretation from a certain point of view. This point of view is, in general, somewhat similar to that adopted by HoLmes ("04) in a general discussion of the same problem. As will appear later however, my position actually differs widely from that of Holmes.

\section{The Methods of Regulation in Turbellaria.}

From among the species of Turbellaria on which we have data regarding regulation a number have been selected as illustrating the differences in the process of regulation in different cases. The forms selected are Bipalium lewense, Cestoplana sp., Planaria maculata, together with a Californian species which resembles it as regards regulative processes Planaria simplicissima, and Leptoplana tremellaris. With all of these forms except $P$. simplicissima I have performed extensive series of experiments.

Only a general account of the principal features of the regulatory process is attempted here. I hope to discuss at another time certain special phenomena which seem to me particularly important.

\section{Bipalium kewense.}

This form, an extremely long and slender tropical land-planarian, marked with longitndinal dark stripes, occurs rather commonly in conservatories, having been introduced with tropical plants.

The replacement of lost parts is usually accomplished in this species with scarcely any outgrowth of new tissue from the cut 
surface, i. e., by redifferentiation of the old parts. Figs. $1-4$ sbow the course of regulation at the anterior end and Figs. 5- 8 the change in proportion and the posterior end. Even the head is formed almost entirely posterior to the cut surface (Figs. 1-4), thongh there is considerable proliferation and alteration of form and structure in the region concerned. The changes in proportion are great and rapid especially in short pieces from large worms (Figs. 5-8).

Fig. 1.

Fig. 2.

Fig. 3.

Fig. 4.
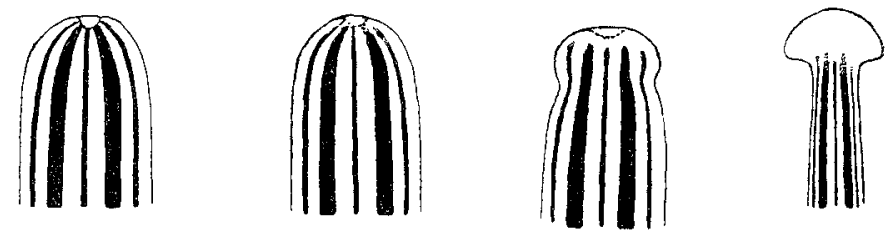

The only other account of regulation in Bipalinm so far as I am aware is that given by Morgan ('O0a) with whose obscrvations my own agree in most respects. Mongav's statements regarding the method of formation of the head are, however, not wholly clear to me, but as I understand them, he regards the process as one of

Fig. $\check{5}$

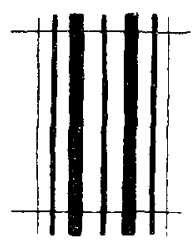

Fig. 6.

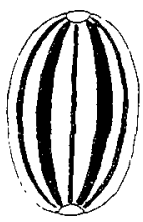

Fig. 7.

Fig. 8.

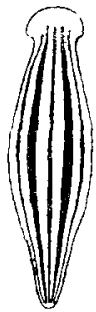

growth of new tissue in the anterior direction from the cut surface, this growth being marked by an extension with the new tissue of the dark pigment bands which thus make it appear as if the head arose wholly, or almost wholly posterior to the cut surface. In my opinion there is absolutely no evidence that the pigment bands extend forward over a growth of new tissue.

Figures 1-4 which are from my own experiments but which are almost exactly similar to MorgaN's Fig. I $A, B, C, G$, show very clearly it seems to me that instead of a forward growth of the pig- 
ment bands their anterior ends gradually disappear. In . Figure 3 the position of the constriction indicating the neck at a time when the cut surface and the very small amount of new tissue growing: from it are still visible is very convincing evidence that forward extension of the stripes does not occur. Sections which I have made of this region also show very clearly that no growth of the pigment bands over new tissue takes place. The parts in the regions where the bauds are present are fully differentiated: only the minute terminal area is new undifferentiated tissue. Of course these regiuns do undergo later extensive proliferation and growth as they are transformed into the new head, but this does not alter the fact that they are posterior to the cut surface and that the head arises by a redifferentiation of an old part.

In certain series of experiments Moman destroyed with a hot needle a portion of the median pigment band at the anterior end of a piece and found that the lateral pigment bands sextended forward while the anterior end of the median band remained some distance posterior to the head (Molicas, 'OOa, Fig. V $1-D$ ). He interprets this result sto mean that the injury to the anterior end of the middle stripe has prevented its extcusion forward at the time when the other bands move forward into the region of the new head and neck (Morgan, '00a, p. 570). This experiment seems to me wholly unconvincing. Since the anterior end of the median stripe was destroyed the lateral stripes necessurily appear to extend farther forward after cauterization than the median stripe. Moreorer, in the closure of the wound made by the necdie the lateral stripes are carried around anterior to the end of the median stripe by the contration which always oceurs. In other words any apparent or real extensionk forward of the stripes which necurs is simply the result of the operation intended as a reveial experincent. Naturally as the pieve becones longer and more slender the artual distance between the end of the median stripe and the anterinr end will increase nuless the stripe is formed anew, which is not the case for a long time. The only extension of the stripes is due to the clange of proportion in the old parts, not to growth anteriorly over new tissue. As in other forms (Cums, 03, $03 \mathrm{a},{ }^{\prime} 05 \mathrm{a}$ ) the change in proportion is closely connected with the movements of the piece and is, at least in large part, essentially a physical phenomenon, though a variety of internal functional changes are of course conditioned by it. MorGax states that he was : unible to determine by meaus of iujuries 
at different points whether the rate of elongation is the same throughout the entire piece". His conclusion is that "most probably it is nearly so since the decrease in breadth takes place at an equal rate at all levels «. This last statement contradicts not only my observations but MoRGan's own figures. He gives several figures resembling more or less closely my Figure 7 and all showing that the decrease in breadth occurs much more rapidly in the terminal than in the middle regions. This point is of considerable importance for the understanding of the changes in proportion and is therefore emphasized.

But the pieces with oblique anterior end afford very strong evidence in favor of the view that no forward extension of the pigment stripes occurs except so far as they share in the general elongation

Fig. 9.

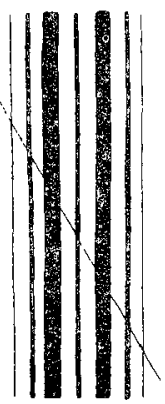

Fig. 10.

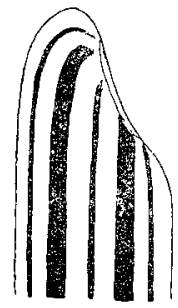

Fig. 11.

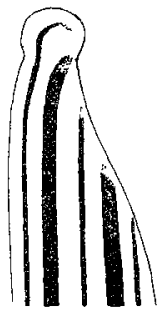

Fig. 12.

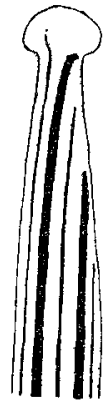

of the body. Figures $9-12$ which are similar to the cases shown in Morgan's Figures II, III and IV, show very clearly that the constriction indicating the neck appears a considerable distance posterior to the tip of the obliquely cut end.

My material did not permit me to determine fully the relation between the position of the new pharynx in a piece and the level of the old body from which that piece was taken. A pharynx does develop, however, in the old tissue at a considerable distance from the ends.

We may, I think, regard it as established that regulation in Bipalium commonly oceurs almost wholly by sredifferentiation " in the old tissues and not by the differentiation of new tissue arising from the cut surface. In the formation of the head a considerable amount of "new * tissue appears but this is practically all posterior to the cut surface. Under certain conditions, however, extensive outgrowth from the ent surface will take place in Bipalium. This 
and the conditions upon which it depends will be discussed elsewhere.

In general, the course of regulation in Stenostoma (CHILD, '02, '03a) is similar to that in Bipalizen; regulation in this form is a process of "redifferentiation" of parts of the old body, though probably here and in Biprtizum as regards the cclls actually involved the process is, strictly speaking, a differentiation. In this case no visible outgrowth of new undifferentiated tissue beyond the cut surface takes place.

\section{Cestoplana sp.}

Certain phases of the phenomena of regulation in this form have been described in the Studies on Regulation (Cmmn, '05b), '05c). A

Fig. 13. Fig. $16 . \quad$ Fig. 17. Fig. $18 . \quad$ Fig. $19 . \quad$ Fig. 20.

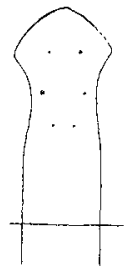

Fig. 11.

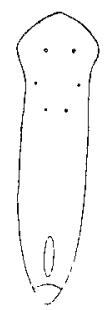

Jị. 15.

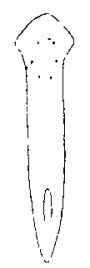

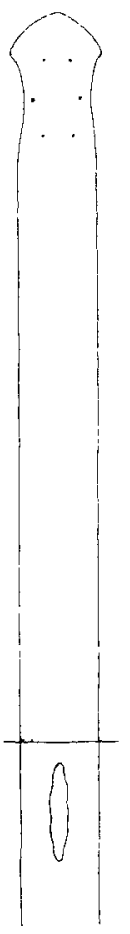
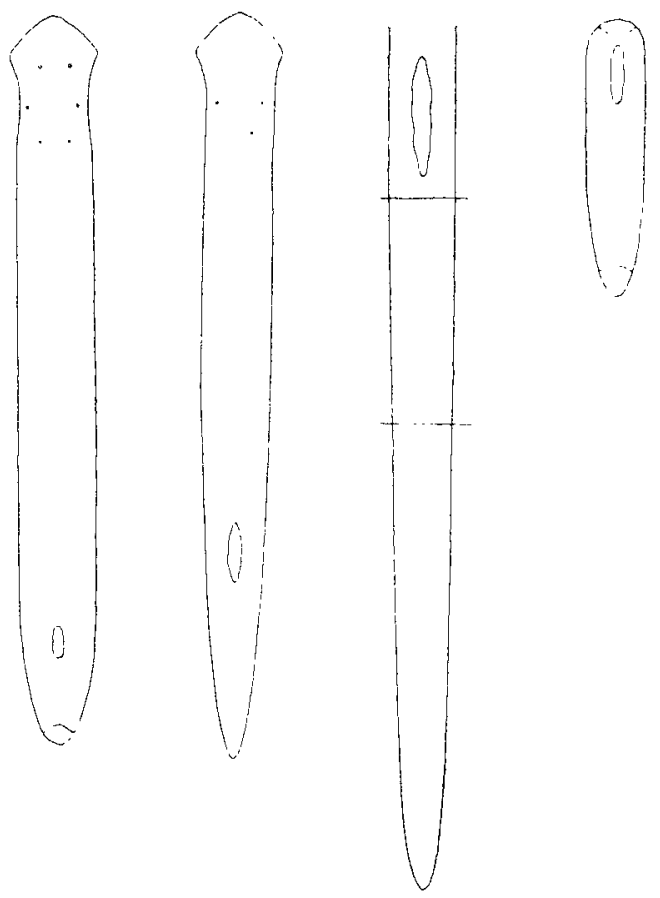

few of the more important points are recalled here. Regeneration from a posterior cut surface is very slight the newly formed portion comprising merely the tip of the tail (Figs. 13 and 14, 16 and 17). 
Fig. 21.

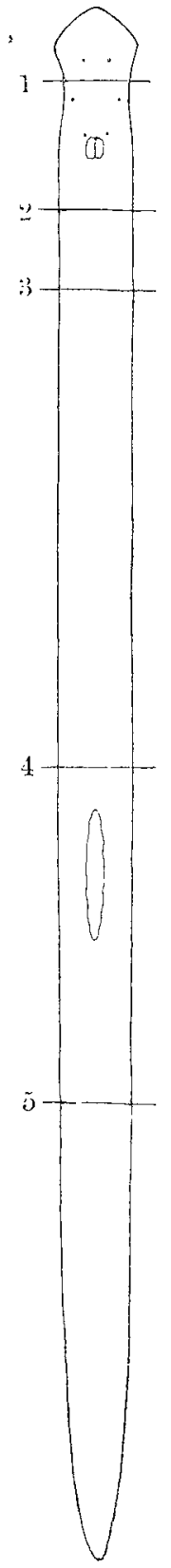

The amount of this posterior regeneration does not vary appreciably with difference in level. Elongation and reduction in width of the parts anterior to the level of section occurs, and within a few days a new pharynx appears in the vold « tissue at a greater or less distance anterior to the level of section. Figures 14 and 17 show the position of the new pharynx at the earliest visible stage in a very short anterior piece (Fig. 13) and in a piece comprising all of the prepharyngeal region (Fig. 16). In the short piece the new pharynx appears very mear the posterior end while in the longer piece is at a much greater distance from this end. After the

Fig. 22. Fig. 23. Fig. 24 Fig. 25. Fig. 26.
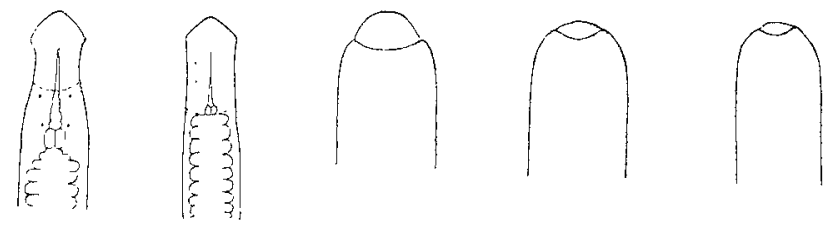

appearance of the pharynx the region posterior to it undergoes considerable increase in length (cf. Figs. 14 and 15, also Figs. 17 and 18) which must be due in part to actual proliferation in this region, though it is in some degree the result of the change in form of this part. In prepharyngeal pieces without the cephalic ganglia the results are much the same, except that the new pharynx is farther from the posterior end. In postpharyngeal picces which of course are deprived of the cephalic ganglia a new pharynx does not usually appear: in a few cases, however, it has been observed and always lies very near the anterior end of the piece (Eigs. 19 and 20), i. e. as far removed from the typical pharyngeal position as in prepharyngeal pieces but in the opposite direction.

Regeneration from an anterior cut surface varies greatly according to the level of the cut surface (CHILD, '05 b). Removal of regions anterior to the cephalic ganglia is followed by complete regeneration of the missing parts as indicated in Figure 22 (cf. Fig. 21, 1). If the level 
of section lies only a short distance posterior to the ganglia (Fig. 21, 2) new ganglia may be formed and regeneration is practically complete except as regards the region between the ganglia and the cut, which is not represented in the new tissue, for the new ganglia lie immediately anterior to the cut (Fig. 23). Posterior to this region the amount of new tissue formed on an anterior cut surface decreases with increasing distance from the auterior end but a head is not regenerated. Figures 24,25 and 26 show the maximal regeneration at the anterior ends of pieces cut at the three levels indicated by the transverse lines 3,4 and 5 in Figure 21.

As I have pointed out (CHILD, '05e), the appearance of the pharynx at some distance from the cut surface indicates that $» r e-$ differentiation « or as I have designated it functional regulation in the old parts is going on. In snch cases as Figures 14 and 17 the region posterior to the pharynx must be regarded as representing in some way and to some extent the postpharyugeal region of a typical specimen. I have called it the functional postpharyngeal region.

Taking this viow we may sum up regarding Cestrplonet as follows: regulation after removal of a posterior part is almost wholly a process of "redifferentiation " in the old tissues, only the extreme tip of the tail being formed by the growth of new tissue from the cut surface. The size of the region involved in this regulatory process differs with the level of section. On the other hand, regulation after the removal of an anterior part consists almost wholly of regeneration; at levels anterior to, in, or not far posterior to the cephalic ganglia regeneration is complete or nearly so; posterior tc these regions a new head is never formed and regeneration decreases in amount with increasing distance of the level of section from the anterior end.

This peculiar combination of different regulatory processes in a single piece is of considerable interest, but although it occurs in other forms the significance has not been recognized heretoforc.

3. Planaria maculata and Certain Other Species.

The remarkable power of regulation in Planaria maculata and related species has long been known and an extensive literature on the subject exists. For the present purpose it is sufficient, however, to call attention to certain of the most important features.

In general it may be said that pieces above a minimal size from any region of the body except anterior to the eyes and perhaps 
the extreme lateral regions usually become complete worms within a few days. So far as I am aware MorgaN ('97) was the first to call attention to the fact that the actual regeneration gives rise only to the terminal portions of the part removed, not to the whole. The new pharynx in most cases arises in the old part, not in the new tissue formed at the cut surface.

The following general statement of MorGaN's ('98, pp. 390-391) is quoted as expressing lis conclusions: "The amount of new tissne is, in a general way, in proportion to the size of the piece. The larger pieces form more new material than do the smaller, yet certain important limitations must be made also to this too general statement. When the anterior end is cut ofl' it is replaced by a new head, but only the head is formed at first, even if the part removed included nuch more than the head. The new worm is, therefore much shorter than the original worm. This result may be expressed in another way; enough now material is added to the anterior end to form a new head and all the material is userl up in the formation of this part. The question at once suggests itself, how do the new worms regain their normal proportions; for the pieces are too broar in proportion to their lewgth and the new pharyux is much too noar the anterior end. The answer to this question was found by measuring the worms from time to time, and the very surprising fact determined that slowly the slape of the worm is altered by the remodelling of the old material. « Doubtless Morgax would also adopt the same view with regard to regeneration at the posterior end of a piece, though $\mathrm{I}$ do not find that he discusses it.

In this same paper a series of experiments is described in which ten worms were divided into twelve pieces each by a series of transverse cuts and the regulation of the different pieces compared. No satisfactory figures of the results obtained are given and the conclusions are stated only very briefly, but it is evident that MoRGAN noted the difference in position of the pharynx according to the level from which the piece was taken. In the most anterior pieces behind the eyes a pharynx appeared near the posterior end largely in the new tissue, in pieces posterior to these in the old tissue near its posterior border, in the next series in the old tissue posterior to the middle, etc., and finally he states without making any distinction as to level that in all pieces posterior to the middle of the body the new pharynx appeared at or near the middle of the old part. But the account of this experiment is concluded with the following state- 
ment: "Again it will be noted that in all the pieces at the end of the experiment the pharynx is relatively much too near the anterior end of the new worms."

There are several points of difference between Morgas and myself that must be mentioned. Murias has not given evidence in support of the statement that the amount of new material formed is in a general way proportional to the size of the part and none of his figures show this relation clearly so far as I am aware. According to my own observations for which the data will be given elsewhere, the relation between size of the piece and the amount of new tissue formed is by no means so simple. Moreover, the $»$ important limitations w with which Morgan follows his own statement destroy most of its significance.

In view of the fact that a regenerated head or tail cut off will be replaced by a new one and that this operation may be repeated almost indefinitely, it is difficult to aceept Morias's conclusion that all the material is used up in the formation of the new head or tail. This cannot be the reason why regeneration ceases with the formattion of these parts.

Moreover, the statement that in all pieces the pharynx is too near the anterior end at the end of the experiment seems to me to he not only in total disagreement with the facts but with Mokisix's own statement that in pieces from regions near the anterior end of the body the pharynx appears near the posterior end. In such pieces the new pharynx always appears a considerable distance posterior to the middle of the piece, and while it does gradually approach the middle, I have never seen a case where it lay much nearer the anterior than the posterior end.

As additional data and for comparison with the fignres of other species a series of figures from some experiments of my own on a Californian species of Planaria are given. This species is essentially similar in most respects to Planaric maculata as regards regulation and will serve therefore as a type for this method of regulation. The figures represent a series of pieces comprising the whole body of a single worm and of various sizes as indicated in Figure 27. The figures are numbered in order from the anterior to the posterior end of the body, the portion of the original body represented by each being indicated in Figure 27. Two figures of each piece are given, one of an earlier the other of a later stage. Each figure is the result of a large number of careful measurements including length, 
Fig. 28.

Fig. 27.
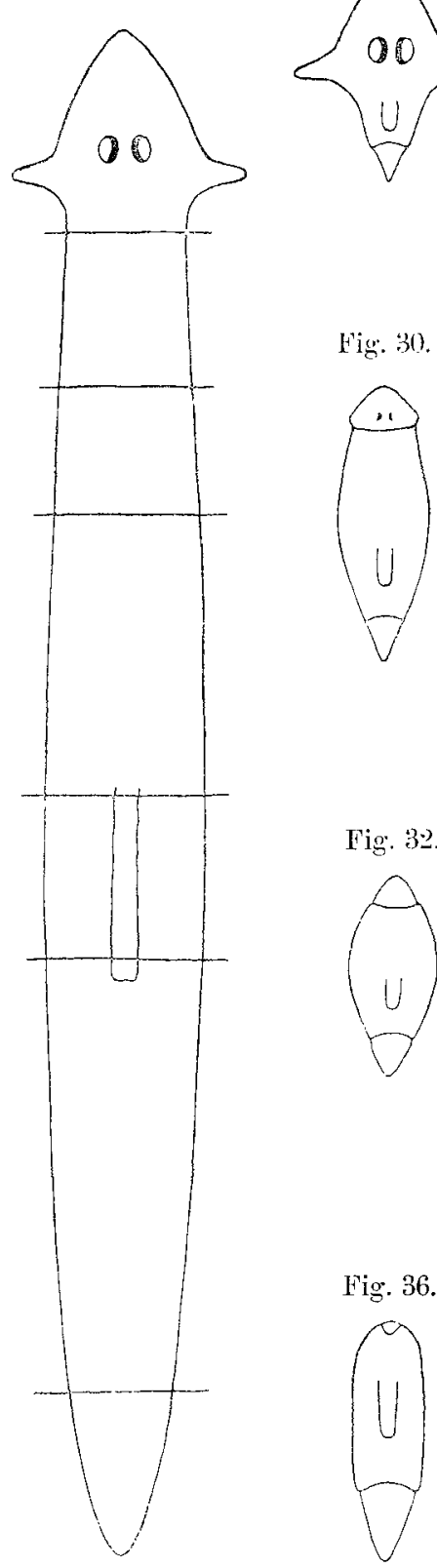

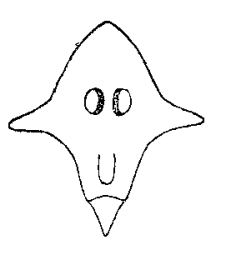

Fig. 29.

Fig. 34.

Fig. 35 .

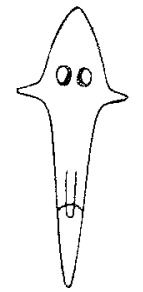

Fig. 30. Fig. 31.

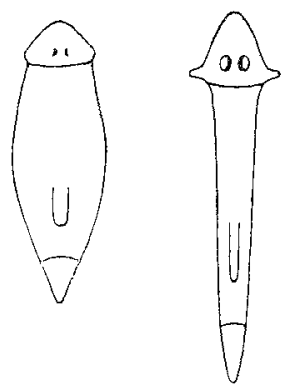

Fig. 32. Fig. 3․

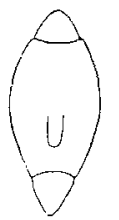

Fig. 36. Fig. 37.
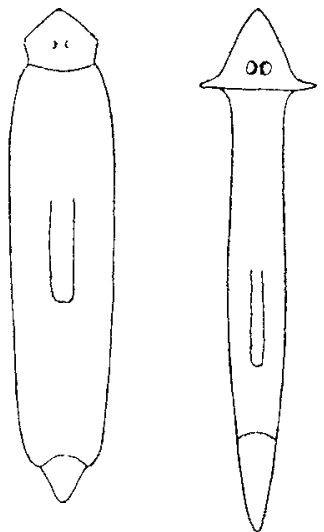

Fig. 38.

Fig. 39.
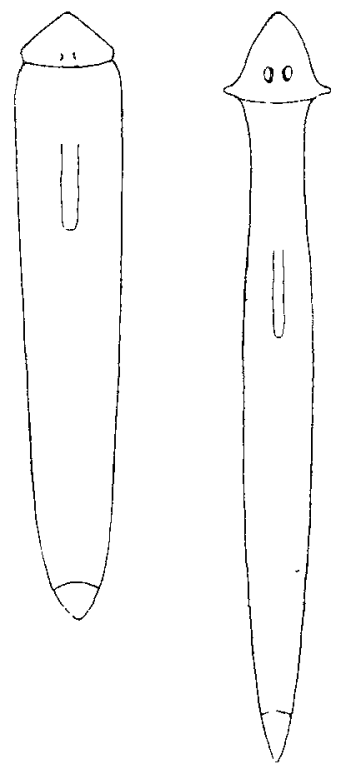

Fig. 40. Fig. 41.

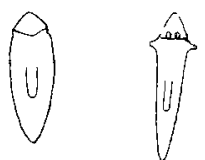


length of head and of anterior and posterior new tissue, distance from anterior end to pharynx, length of pharynx, width of head, length of anricles, width of sneck k, width at middle, and width at boundary between posterior new and old tissue. The accuracy of the measurements is sufficiently evident from the similar relations between the two stages in all pieces. I believe it is impossible to obtain any adequate or exact idea of the processes of regulation in such forms as these withont these extensive and frequently repeated series of measurements. Omission of measnrement is responsible for many loose and incorrect statements in previous work on these forms.

Without attempting full consideration of the points suggested by these pieces, attention is called to certain important features.

As regards the amount of new tissue formed at the posterior end of the piere it is elear that no direct relation between this and the size of the picre exists. The anomat of new tissue is least in the largest piere ( $\mathrm{H}$ ig. 39) thongh at an earlier stage the piece showed about as much new tissue as others. The present series is not especially favorable, however, for detailed consideration of this point since both size of the piece and level of the body are concerned. In order to obtain exact data we must compare on the one hand pieces of different size with posterior ends at the sime level of the body and on the other hand picces of the same size with posterior ends at different levels. Series of comparisons of this sort which I have made indicate that while a certain influence of size exists the lcvel of the body represented by the posterior end is the more important factor. These points will bo discussed elsewhere. As regards the anterior now tisste the case is somewhat similar: the size of the new liead depends in some degree on the size of the piece as is clear from my tigures, but the influence of the level is complicated by certain physiological conditions in the region posterior to the pharynx, which afford indisputable evidence that there is a physiological, if not a visible morphological preparation for fission.

The piece from the old pharyngeal region shown in Figures 36 -37 did not regenerate a head. As Mongas and others have noted and as my own observations also show this failure to form a new head is frequent in pieces from this region. Diseussion of the probable reasons for its occurrence is postponed to another time.

The first point of importance for present purposes is that neither the anterior nor posterior regeneration replace more than a small portion of the part removed, except of course where the pieces are 
nearly terminal. This has already been recognized by Mongan as noted above. As regards the position of the pharynx, the level represented by the piece is the important factor. In pieces from the old prepharyngeal region the new pharynx is posterior to or at the middle (Figs. 28, 30, 32, 34), being most posterior in the most anterior pieces (Fig. 28) and nearest the middle in pieces near the old pharynx (Fig. 34). In pieces from the pharyngeal region the pharynx appears about the middle of the old tissue. In pieces posterior to the pharynx the position of the pharynx ustally shows a totally different relation to level: When the anterior end of a postpharyngeal piece lies in the anterior half of the postpharyngeal region the pharynx appears considerably anterior to the middle (Fig. 38) no matter what the level of the posterior end, but if the piece lies wholly within the posterior half of the postpharyngeal region the pharynx appears, not in the extreme anterior part as might be expected, but in the middle (Fig. 40). This conclusion is based on data from more than a hundred specimens including both $P$. maculata and the Californian species. As I hope to show later this peculiar relation, to which no attention has been paid by others, is connected with the occurrence of fission in these species.

In later stages an apparent migration of the pharynx toward the middle of the body, its typical position, occurs. This is indicated in most of the figures of later stages (Figs. 29, 31, 33, 35, 37, 39, but still later stages are more favorable. The apparent migration is undoubtedly the result of relative increase in size of one part of the body, either the postpharyngeal or the prepharyngeal, at the expense of the other, but it seems to me very improbable that any extensive migration of actual tissues takes place. The change concerns nutritive material rather than tissues. As is well known extensive changes especially in the intestine go on in the old parts in consequence of which the regions anterior and posterior to the new pharynx become respectively typical prepharyngeal and postpharyngeal regions, i. e., these regions undergo redifferentiation. In these species then both anterior and posterior regulation are a combination of regeneration and redifferentiation. The figures readily permit comparison with Bipalizun and Cestoplana without further discussion.

\section{Planaria simplicissima.}

The species which Morgax has recently ('04b) called by this name is the same which in his earlier papers ('01a, etc.) was called 
P. hugubris. Morfas has used this form for experiment to a considerable extent, but I have been unable to find it in the localities aceessible to me, and hence depend upon his data. Figures $42-46$ illustrate the course of regulation in pieces from three different levels. All of these except Figure $4 t$ are diagrammatic figures drawn from

Fir. 49.

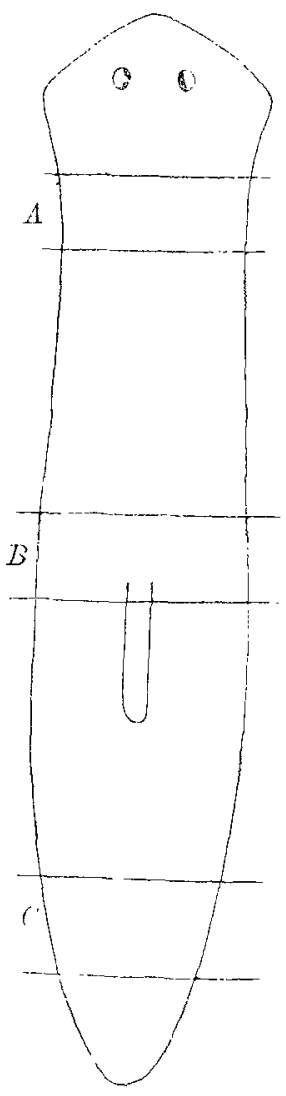

Fig. 43.

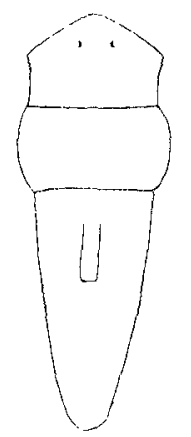

lig. 44.

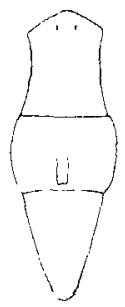

Fig. 45.

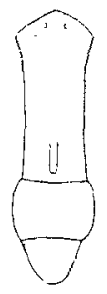

Mondary figures (01a, Fig. $3.4 b$ and $C(c)$. Wigure 14 is a figure marde up from: Momatis's description of regulation in the middle region. Mokitu's aceount ('01 a, pp. 186-188) is as follows: If we compare the development of a narrow cross-piece of $P$. lugubris from the region just betind the bead, Fig. $3 A$, with the regeneration of a similar piece from the middle of the body, Fig. 3, $B$, and with one from the posterior part, Fig. 3, ' Tig. $42 A, B$, and $C$ of the present paper), we find important differences take place in the regeneration of the pieces. The anterior piece it produces little more than a new head at its anterior end and the now head is not carried further forward by the subserquent growth of new material behind it, Fig. $A, b$ (Nig. 43 of the present paper). The same piece prodnces at its posterior end a new tail, entaining a pharynx, and if the piece is fed this new part continues to grow longer, carrying the pharynx more posteriorly until an equilibrium is reached between the new and the old parts plus the new head. After this the entire piece will grow larger if the feeding is continued. If the new worm is not fed the tail grows longer, but more slowly, and the oid part continues to 
get narrower from side to side. The process goes on until the typical proportions of the parts are attained, that is until the new pharynx has been carried to its proportionate distance behind the head. If the piece is now fed it will enlarge at a proportionate rate in all its parts.

*The middle piece $B$ produces a new head at the anterior end. A new tail appears at the posterior end and a new pharynx appears in the middle of the old part in the old pharyngeal chamber (Fig. 44 of the present paper). The new parts at the two ends grow longer at about an equal rate; the head being carried forward as the result of new tissue appearing behind it. I have not made out where the region of growth lies in the posterior part, but to judge from what happens in the more anterior pieces, where the pharynx is carried backward by growth in front of it, it seems probable that the new growth in this case also is near the base of the tail, or throughont the entire new part. If the piece is fed the two new ends grow rapidly, and the middle part remains about the size it had been reduced to as a result of the first formation of new material at the two ends, or it may grow larger. If the piece is starved the old part is further reduced in size until an equilibrium is established. A smaller worm results.

"The posterior cross-piece $C$ produces a head at the anterior end though it is very noticeable in this form (but not in $P$. maculata) that more new material appears before the head differentiates (and there is a delay of several days , as compared with the development of more anterior regions (Fig. 45 of the present paper). A short tail appears at the posterior end of the piece. A new pharynx appears just behind the head in the new part where the new and old parts are continuous. It lies at first almost in the head. New tissue continues to develop in the anterior part, and as this growth takes place mainly between the liead and the pharynx the former is carried further forwards. If the worm is not fed the old part decreases, especially in breadth, as the new part develops. If the piece is fed, the new parts grow faster; and the old part loses less, or may remain the same size.

"These results show that cross-pieces from different parts of the body regenerate in different ways. The old piece acts as a barrier and holds the same relative position in the new worm that it held in the old. The nature of the old piece is the determining factor in the subsequent growth in the new part. There is nothing, as far as 
could be foreseen, that would prevent an anterior piece growing with equal rapidity at the two ends in order to reach the symmetrical condition, but this does not occur..... It is important to note that in both anterior and posterior pieces the region of growth lies in front of the pharynx."

A little later the following statement is made regarding the appearance of the new pharynx anterior to the old tissue in pieces from the postpharyngeal region: "The old piece has acted as a barrier preventing the new pharynx from appearing at its proportionate distance from the new head as would be more nearly the case if it dereloped at the posterior eut edge. The result shows that the ordinary idea of polarity does not apply here, since a posterior structure - the pharynx - appears at the anterior end of a piece if this piece comes from behind the pharyax in the old worm. It is not simply a question of anterior and posterior ends of the crosspiece, but of the relation that this piece held to the parts of the original worm, that determine its action; and this is all the more important since it has been shown that from any part of the piece any part of the new worm may arise."

Morgan's conclusions regarding the position of the region of growth are it seems to me contradicted by the figures given above and many others in his paper. It is difficult to understand how a region of growth in front of the pharynx in the case of Figure 43 for instance can produce a long postpharyngeal region such as this specimen possesses.

But matters of detail aside, the important point is that in this species regulation consists chiefly or wholly of the formation of new tissue from the cut surface and the differentiation of this tissue into the missing parts. In pieces from the middle regiun of the body, lowever, the pharynx does appear in the old part. The influence of the level which the piece originally occupied is very marked.

The position of the pharynx in pieces from different levels is exactly what may be expected in cases where regulation is chiefly regeneration. How this varying position of the pharynx is in any way connected with polarity as Morgax seems to believe it is, I cannot understand. This is no more a polar phenomenon than is the position of the pharynx in Planaria maculata near the posterior end in anterior pieces and anterior to the middle in postpharyngeal pieces.

The differences in method of regulation between this and the 
forms previously described is clearly visible from the figures without further discussion. The question as to the conditions which determine these differences, especially such as exist between this form and the closely related $P$. maculcta is one of great interest; an answer to it must afford us an insight into the nature of the processes concerned. Moratn, however; has made no attempt to consider it, having contented himself with pointing out rery briefly what some of the differences are.

\section{Leptoplana tremellaris.}

The various features of regalation in this polyclad have been described in certain of my Studies on Regulation (Cmrn, '04a, '04 b, '04e, '05a). The most important points are briefly reviewed here.

In general, regeneration is the chief method of regulation in Leptoplana. Posterior regeneration is qualitatively complete at all levels posterior to the middle of the cephalie ganglia (Figs. 46-52) and is also quantitatively complete provided the piees are fed. In the absence of food the regenerating part grows at the expense of the old which is reduced and regeneration is greatly retarded or ceases in most cases before the new part attains its typical proportions. Anterior regeneration is complete only at levels anterior to the middle of the ganglia (Fig. 53). Posterior to the ganglia the amount of new tissue formed is no great and a typical head never results (Figs. 54-57) though if the level of section be near the ganglia some approach to head formation may occur.

Certain of my observations on the amount of regeneration at different levels of the body are important for present purposes. If, for example, we compare pieces from which posterior parts have been removed at three different levels (Fig. 46, 3, 4, and 5) we find that while in pieces without food the new part never attains the size of the part removed, yet the relative, and in general the absolute amount of new tissue formed decreases with the size of the part removed. Figures $47,48,49,50,51$, and 52 show respectively an early and a late stage of regeneration from the three levels 3,4 , and 5 in Figure 46. It is evident at once that the amount of regeneration is relatively much greater in the smallest piece from which the largest portion has been removed (Figs. 47 and 48); next in order is the piece from which about half the body has been removed (Figs. 49 and 50) while the piece from which only the most posterior portion has been removed regenerates least of all (Figs. 51 and 52). 
In many cases the posterior regeneration from the prepharyngeal levels exceeds not only relatively but in absolute amount as well as that from the middle regions of the body; though in the cases figured (Figs. 47, 48, 49, 50) the absolute amount is slightly greater in the

Fig. 46.

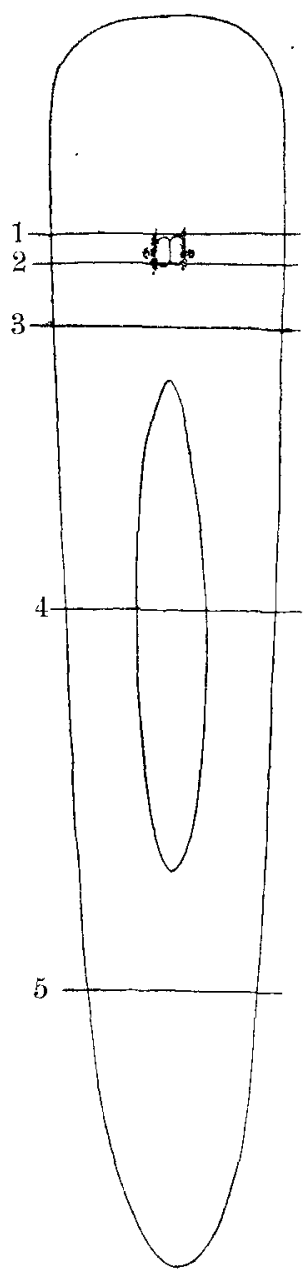

Fig. 47.

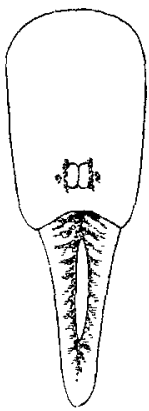

Fig. 51.

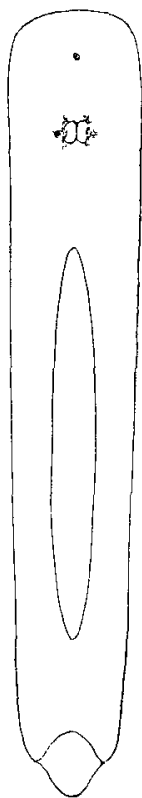

Fig. 48.

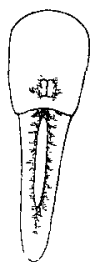

Fig. 52 .

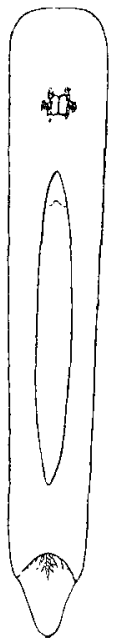

Fig. 49.

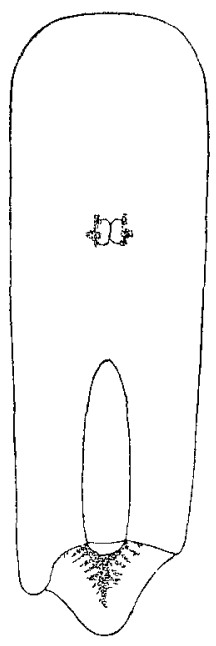

Fig. 50.

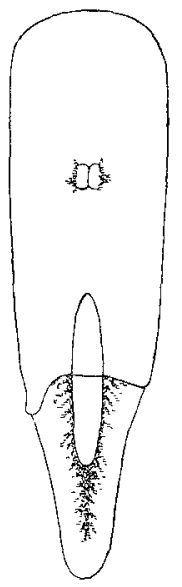

larger piece but the difference is comparatively slight. If amount of material in the piece were the chief factor concerned we should expect that the smallest piece would show least regeneration, the largest most. It is evident that other factors are chiefly concerned here. 
It will be noted that as regards posterior regeneration Leptoplana is similar to Planaria simplicissima. There as here the amount of regeneration decreases with approach of the level of section to the posterior end of the body. As I showed in a previous paper (CHILD, '04b) the result is the same if the ganglia are removed in all cases though in such pieces the total amount of regeneration is less at all levels.

But as regards anterior regeneration very different results are obtained. Regeneration from levels anterior to the cephalic ganglia or through their anterior half is complete (Fig. 53) at all levels posterior to the middle of the ganglia regeneration is very incomplete,

Fig. 53 .

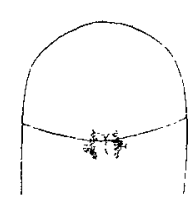

Fig. 54 .

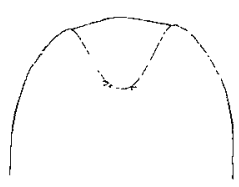

Fig. 55.

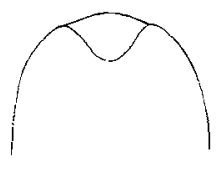

Fig. 56.

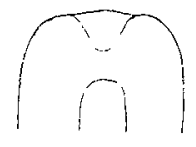

$\mathrm{Hig} . \tilde{5} 7$

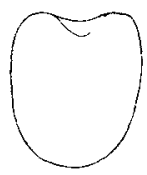

only a small mass of new tissue which fills the concavity of the cut surface being produced (Figs. 54-57). except in a few cases where section was made immediately posterior to the ganglia, in which case a pointed outgrowth sometines appeared which functioned in some degree like a head (CHnb, 'Ot 4 cl. Moreorer, in postganglionic regions the amount of regeneration decreases with increasing distance from the ganglia. Figures $54-57$ show respectively the total anterior regeneration from the levels $2,3,4$, and 5 in Figure 46 . Here the effect of the nervous system upon anterior regeneration is more clearly marked than in Cestoplena for in that form regeneration of the ganglia themselves was possible at levels immediately posterior to them, though not from those farther posterior.

In most of the polyclads examined and in a large number of fresh water rhabdocoels with which I have experimented the process of regulation is essentially similar to that occurring in Iseptoplana. 


\section{The Relation Between the Nervous System and Form Regulation in Planarians.}

In his first paper on regeneration BARDEEN ('00) stated that a portion of the central nervous system was necessary for the occurrence of regeneration in Planaria maculata.

LiLlie ('01) showed that picces of Dendrococlum lacteum from regions posterior to the pharynx reacted much less readily to stimuli than prepharyngeal pieces and that regeneration of the head, which takes place rapidly in prepharyngeal pieces does not occur in those from the postpharyngeal region. He is inclined to believe that the external conditions at the anterior end, i. e., contacts, etc., occurring. during locomotion and other motor reactions may determine the formation of a head there. At any rate a relation of some sort between the nervous system and regeneration seems to exist, but I think it probable that the external conditions are not as LiLuLe believes the determining factors. Pieces of Ilanaria maculati although capable of coordinated locomotion often show scarcely a trace of movement when left undisturbed and may even become envcloped in slime until the new head and tail have developed to a considerable extent. Monicas ('01 b) says, however, „I can state that a new brain develops even when none of the lateral cord is present". This statement refers to narrow pieces cut from the extreme lateral regions in Planuria.

In a later paper, Balidees (03) reasserts his former view that a portion of the nervous system must be present in order that regeneration may oeeur and confirms it by various experiments.

Still more recently Morgan ('O4a) has again asserted that in both $P$. maculata and $I^{\prime}$. simplicissima lateral pieces containing no portion of the longitudinal cords are able to produce new heads, and has confirmed his earlier statements by section of the specimens employed.

In several of the Studies on Regulation (CHILD, ${ }^{\circ} 04 \mathrm{~b},{ }^{\circ} 04 \mathrm{c},{ }^{\prime} 05 \mathrm{~b}$, '05c) I have pointed out the close relation existing between the nervous system and form regulation in Leptoplanct and Cestoplana and in an earlier paper a similar relation was shown to exist in a peculiar process of regulation vecurring in Stenostoma. The probable nature of this relation has been discussed in those papers and it is sufficient here to recall my conclusion that it is essentially functional in character and not due to special formative or "trophic stimuli. Experimental eridence in faror of this riew which seems to me very 
strong was also given in these papers especially in the Studies on Leptoplana (CHILD, '04 b, '04c).

The study of the motor reactions of the pieces affords a clue to the degree of cephalization present in the nervous system of various species and we find a remarkable parallelism existing between this and the character and amount of form regulation.

But the difference of opinion between Bardeen and Morgan requires brief consideration. In this connection I have redrawn

Fig. ธิ8.

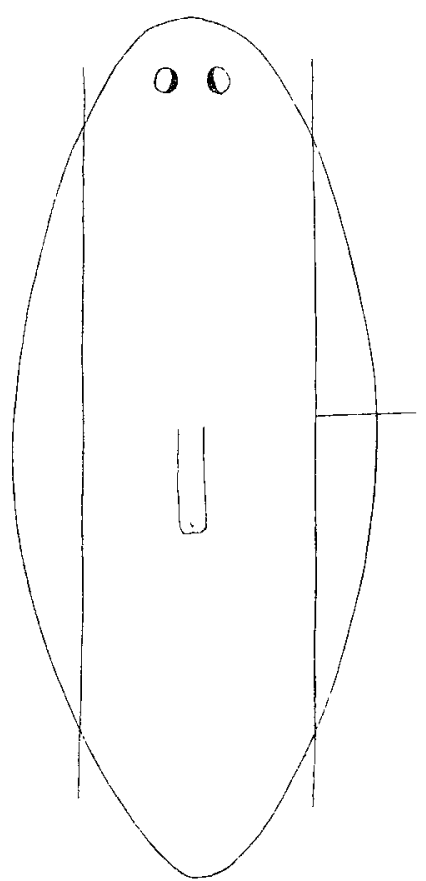

Fig. 59.

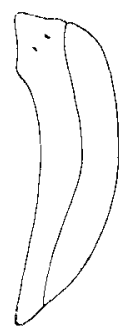

Fig. 61.

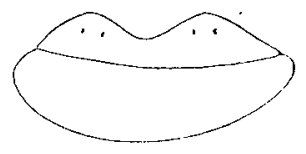

Fig. 60 .

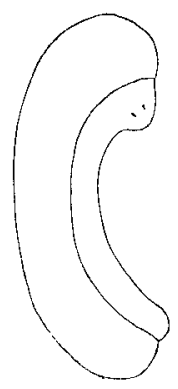

Fig. 62.

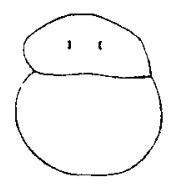

certain of Morfan's figures as Figures 58-62. Figure 58 represents of Moncxan's diagram showing how the cuts were made in experiments on Planaria simplicissima in which the pieces regenerated. The worm is shown in contracted condition. Even if these or other similar pieces which give rise to new heads lie wholly lateral to the longitudinal cords one point still remains to be considered: the longitudinal cords give of lateral branches and it is not impossible that these lateral branches might become united longitudinally or since the nervous system in Planaria is not highly centralized, that the presence of the basal portion of a branch would be sufficient to 
permit regeneration of a head. If the latter suggestion is correct we can readily explain the formation of heads along the cut surface of the piece instead of at its anterior end - a frequent occurrence two heads being sometimes found in this position (Figs. 61 and 62). If this is the explanation of these eases the formation of heads in this position does not signify a change of polarity since the heads form at the central end of the part of the nervous system present. Figures 59 and 60 show cases in which the heads appeared at the anterior end or on the anterior portion of the lateral cut. Figure 59 is a piece from $P$. maculate, the others are from $P$. simplicissima.

In a footnote Morgan $(04 \mathrm{a}$, p. 693$)$ calls attention to the fact that even in narrow lateral pieces some of the lateral nerve paths are present« but regards their significance as donbtful. My own observations along this line - still unpublished - indicate that, both possibilities mentioned above, longitudinal union of the lateral branches and the formation of a new head about the basal portion of a single branch, are realized. Morcover, the longitudinal cords in planarians are not sharply differentiated from the surrounding tissues and it is frequently impossible to determine with certainty whether a piece contains a smilll part of the longitudinal cord. or not.

It seems probable then that the differing opinions of MongaN and BARDeEn call be reconciled. BARDiens's statement that some part of the central nervous system must be present in order that regeneratiou may occur is probably eorrect in a physiological sense for in these forms the lateral branches of the longitudinal cords possess in greater or less degree the functional characteristics of the central nervous system. On the other hand, Morcan's statement that regeneration is possible in pieces containing no part of the longitudinal cords is also doubtless correct.

I have been able, moreover, in certain cases to correlate the replacement of certain regions with the presence of particular regions of the nervous system. In Leptoplana (Cinno, '04c) at least half of the cephalie ganglia must be present in order that complete regencration of a head may occur. Posterior form regulation may, however, be qualitatively complete including the formation of a pharynx in both Cestoplana and Leptoplana where the ganglia are totally absent, but all new parts are smaller than when the ganglia are present. Moreover, quantitative correlations between regeneration and the portions of the longitudinal cords present exist in Leptoplana. In picces containing the anterior part of the cords regeneration is 
always greater in amount than in those containing only the posterior portions: the same is true as regards the anterior end in Cestoplana. On the whole we may conclude that the nervous system is an important factor in form regulation in planarians and probably also in other species which possess it. And in my opinion it is important because it plays a large part in determining the functional conditions to which the various parts are subjected.

\section{Discussion and Interpretation.}

\section{The Relation Between Function and Form.}

It has long been known that alterations in the intensity of functional activity bring about changes in the size of certain organs, i. e., hypertrophy or more or less complete atrophy may occur. Moreover, as various authors have demonstrated the relations of the struetural elements of bone and tendon, organs apparently possessing a high degree of stability, may be completely altered experimentally by altering the mechanical conditions, which in these cases are essentially the functional conditions. In short, the form and structure of various parts is dependent in greater or less degree npon the functional conditions to which those parts are subjected. The extent and importance of this relation and its significance with respect to the general problems of biology has not apparently been fully realized.

If the functional relation possesses any general significance we must regard the typical or *normal form as representing in some degree a condition of physiological equilibrium, i. e. the relative sizcs and proportions of parts are in greater or less degree an index of their relative functional activity. This is of course a matter of common knowledge, at least as regards certain organs.

In the presence of a surplus of nutriment this equilibrium may as is well known become more or less widely altered, i. e. certain parts may be more affected than others, though indefinite growth is prevented in most species by the limited capacity of the organs for the transformation of energy, this being of course one element in their functional activity.

In the absence of nutriment, however, other sregulatory" changes in metabolism occur and the physiological equilibrium is altered in a different direction. Nutriment for the organs is obtained from reserves if such are present, and in their absence or after their dis- 
appearance certain parts of the body furnish nutriment for others: in consequence certain parts may undergo more or less complete atrophy during starvation, their substance going to supply the deficit in other parts. Attention has often been called to the remarkable character of this "self-regulation " in that those organs least essential for continued existence are the first to undergo reduction or atrophy while those most essential are the last to be attacked.

In my opinion these facts demend a physiological not a morphological interpretation. There can be little doubt that the various degrees of persistence of organs during starvation is an indication of their relative functional condition rather than of their importance to the species, though intensity or constancy of function is an indication of the importance of a part. But the importance of these organs is the result not the cause of their functional condition.

It seems probable, moreover, that we shall find the interpretation of the various aspects of " self regulation " of metabolisin, not in adaptation but in the laws governing physico-chemical phenomena in general. The laws of chemical equilibrium and the recognition of the reversibility of katalytic processes are undoubtedly of the greatest significance in this connection.

Form and structure in general are in the final analysis the visille expressions of dynamic conditions. In the organic world we may substitute "functional " for sdynamic" provided we use the term in its widest significance, not merely in the narrow sense of the specialized activity of the differentiated complex which we commonly call an organ. We must therefore seek to interpret structure in terms of dynamie conditions or function; in other words morphological facts demand consideration from the physiological point of view.

The attempt to interpret organic structure as the direct result of chemical composition or molecular arrangement has proved unsatisfactory in many cases and especially in connection with regulatory phenomena. It is not improbable that certain so-called protoplasmic structures may be essentially of this nature, but it by no means follows that all other organic structures are similar in character. In any case the development of organic structure is essentially a functional process. The idea of "formative substances" while it may express in a general and naive manner certain correlations existing in the organism must, I believe, give way sooner or later to the idea of $\gg$ functional complexes as the formative agents.

The quality and intensity of functional activity in a given part 
of a living organism depend essentially upon three factors, viz., 1) the functional capacity or functional potence; 2) the relation to other parts; 3) external conditions; or briefly put with respect to the organism as a whole they depend upon internal conditions and external conditions. The functional potence of the part is in itself the result of the structure, i. e., of the dynamic conditions in the part, the relations of its elements to each other and its past and present relations to other parts and to external conditions.

The relative importance of the three factors must differ widely in different cases, but they are all more or less closely correlated. For example the functional potence of a part or its relation to other parts may determine more or less completely the external conditions to which it is subjected. On the other hand external conditions or relation to other parts or both may determine the functional condition. It follows then that in considering the relation between function and structure in a given case we must take account of all these factors.

The phenomena of regeneration in general constitute a most important field for the analytic study of the relation between form and function. Here we often hare it within our power to alter experimentally all three of the factors above mentioned and so to determine the relative value of each in particnlar cases. This to my mind is the most important aspect of this field: it affords the only analytic method for determining the physiological conditions involved in the derelopment of form and structure. But since a large part of the work accomplished in this field has been dominated and directed by morphological rather than physiological conceptions the frequent failure to reach general conclusions of importance, or indeed any conclusions at all is perhaps not to be wondered at. On the other hand the conclusions of Driescr and other neo-vitalists remove the phenomena concerned from the proper field of science at least for the present. Such conclusions are, whatever else may be said of them, so obviously premature in the present state of our knowledge as scarcely to merit consideration.

But postponing for the present further general discussion the important point is whether an interpretation of the facts is possible from the point of view suggested above. In my Studies on Regulation (CHLD, '02-'05d) attempts have been made in this direction, and in the following paragraphs $I$ have endeavored by the analysis of further facts to extend and confirm the conclusions reached from previous observations. 
2. Different Forms of Regulation and Their Significance.

\section{a. Redifferentiation.}

The removal of a given part, e. g., the anterior or posterior end must alter internal conditions to a considerable extent in the regions adjoining the cut surface. In the first place a functional complex previously present is no longer present: since this complex was in organic connection with the parts remaining certain conditions previously present in these are now absent, moreover, stimuli and other changes of energy which were previously transferred from other parts to the part removed can no longer be so transverred. It follows that removal of a given part may alter to a greater or less extent the functional conditions in remaining parts; for example, removal of the head and ganglia in Leptoplana alters the conditions in the posterior piece to such an extent that the reactions and motor phenomena in general are widely different from those occurring when the ganglia are present. On the other hand the removal of the head and sanglia in Planarica maculata alters the motor phenomena to some extent yet they are still qualitatively very similar to those occurring in the presence of the ganglia, the alteration being largely quantitative.

If the change in functional conditions consequent upon the romoval of a given part does not exceed a certain limit, the regions adjoining the part removed are subjected in consequence of the removal to conditions approaching in greater or less degree those existing before removal in the part removed: this similarity in conditions may apply to both external and internal conditions or chiefly to internal. For example: after removal of the anterior or posterior end in Bipalinm or Planaria mroulate the terminal regions of the piece remaining are subjected to conditions somewhat similar to those existing in the terminal regions of the part removed. The anterior end of a headless piece of Planaria is subjected to external conditions more or less similar to those to which the old head was subjected; moreover, its relation to the other parts of the body is more or less like that of the head. Stimuli resulting from forward movement affect it first and are transmitted from it to other parts, ete. Functionally speaking it serves in some degree as a head. The case is similar as regards the posterior end. After removal of the original posterior end the posterior region of the piece functions in some degree as a posterior end, or to put the matter more strictly its 
functional relations with other parts are more or less similar to those of a »tail " or posterior end. As I have shown in various papers (Child, '04b, '04c, '05b, '05e) observation of the pieces is quite sufficient to demonstrate the correctness of these statements as regards motor phenomena and these play a large part in the functional activity of these forms and can undonbtedly be considered as to some extent an index of functional condition in the various regions. Furthermore these functional relations are intensified by the fact that in the absence of a given part the motor phenomena in the parts adjoining that removed are often greatly increased in intensity. For example if the posterior half of Leptoplana be removed and the anterior half strongly stimulated it attempts to move forward as a normal animal would move under such conditions, viz. by attaching the tail and forcibly elongating the body. But no tail is present, consequently the posterior end of the piece functions in the most intense manner. I think it is not going too far to say that in such cases the part remaining "attempts" to use its posterior end as a tail.

In short we may say that where the functional complex is not too greatly altered by removal of a part a certain degree of functional substitution for the lost part takes place in the part remaining. In such a case as Cestoplanc this functional substitution is very complete at the posterior end almost immediately after section. The posterior end of the piece serves as a itail for attachment apparently almost as well as the original tail. In Leptoplana the substitution at the posterior end is much less complete.

If the functional substitution of a part for the part removed involves a considerable region of the piece that region will undergo more or less redifferentiation according to the degree of change in function. And here I believe the effect of what we may call practice must be considered. It is a fact of common knowledge that continued function of a part in a particular manner results in more perfect function. As a matter of fact this change is probably fundamentally a *redifferentiation $*$ or a differentiation in response to functional conditions. Thus in these forms, provided substitution occurs to a certain extent, a-certain amount of redifferentiation takes place which renders possible a greater degree of substitution and so on until the functional substitution and the redifferentiation may both become complete.

Another point must also be considered here, viz. the size of the region involved in this substitution: if this region is relatively 
much smaller than the original part which it represents, increase in size, which is not essentially different from functional hypertrophy must occur if we admit that the relative sizes of parts are in some degree an index of their relative functional condition. In other words if the part undergoing redifferentiation is relatively smaller than the part which it represents or if marked change of form results from the substitution, growth - usually proliferation will occur in it until it attains or approaches the size and form correlated with its relative functional condition as compared with other parts. The formation of the head in pieces of Bipalium is an excellent example of this case. In starving planariins this condition is not usually fully attained before death occurs since the relative atrophy of the other parts occurs with increasing slowness as equilibritum is approached. Moreover, as I have pointed out, in connection with the postpharyngeal region of Cestoplana (CuLn, '05b, '05c) the direction of the change may even be reversed in later stages of starvation where the functional activity of certain parts decreases.

In short redifferentiation occurs as the result of a functional substitution of a larger or smaller part of the old tissues of the piece for the part remored; the substitution may be imperfect or incomplete at first and gradually attain completeness. In consequence of this functional substitntion the structure of the part involved is altered until it comes to resemble more or less closely that of the part removed. In such a case little or no actual regeneration, i. e. formation of new tissne from the cut surface will take place, simply because there is little or no adequate stimulus to growth in this region since it represents functionally only the extreme terminal region of the part removed, other regions being represented by parts anterior or postcrior (or lateral or oblique for these cases do not differ in prineiple). It is evident that the vecurrence or non-occurrence of this functional substitution and consequent redifferention must be determined on the one hand by the functional and consequent structural specialization of the parts concerned and on the other by the alteration of the conditions due to removal of the part. Thus for example, in Bipalium and Cestoplana functional substitution is practically complete at the posterior end and scarcely a trace of regeneration occurs here, the whole process being one of redifferentiation. This is becanse the functional conditions in the posterior region of any piece are not very widely different from those at the original posterior end and are not greatly altered by section. As regards the 
anterior end, however, the two forms differ widely: in Bipalium functional substitution is practically complete here also, and conditions are not greatly altered by section, since the headless piece functions in muoh the same manner as a normal animal. Hence practically no regeneration occurs, the new head being formed by redifferentiation, of the old part, involving to be sure extensive proliferation, but all posterior to the cut surface. In Cestoplana on the other hand the functional conditions in the piece are so widely altered by removal of the head that its reactions are much changed (See CHuld, '05b). Moreover it is clear that the head of Cestoplana is a more highly specialized functional complex than that of Bipalium since its removal brings about much greater changes. Functional substitution of the old part for the part removed is very imperfect, hence redifferentiation does not occur and indeed regeneration is possible only when the level of section is not far posterior to the ganglia.

Intimately connected with the process of redifferentiation of old parts is in many cases the change in proportion of the whole. In the planarians this consists commonly of a reduction in width and an increase in length of the body. This has been regarded by MonGAN and Driesch as one of the most remarkable features of regulation resulting in the return to normal proportions. I have shown, however for Stenostoma (CHILd, '03a) and Leptoplana (CHILd, '04a, '04 b, '04 c, '05a) that the change is largely mechanical and connected with the conditions resulting from movement. This becomes all the more evident when we consider that this change does not invariably bring about return to normal proportion but may, if the conditions of the experiment permit, proceed in the opposite direction (ChILd, 02 , '05c), or may result in a form widely different from the typical (Crricd, '04a). In general a direct correlation between the degree and kind of ehange and the mechanical conditions connected with motor activity can be established. Of course other factors enter when we consider the relative size and proportions of particular organs, but for these cases the relative functional condition of parts affords a sufficient explanation.

The mechanical factor in these changes of proportion must not be neglected as it suffices to clear up many otherwise obscure phenomena, nor should it be confused with the more complex physiological factors of form-regulation. This confusion occurs in the term $\gg$ morphallaxis" employed by Morgan. As used by him this term includes processes of widely diverse nature, as I have attempted to show in 
various papers. It is in no sense analytical and must therefore be abandoned. We cannot gain an insight into the phenomena of regulation by grouping together factors of totally different kind and value.

\section{b. Regeneration.}

Turning now to the consideration of conditions which determine the occurrence of regeneration as opposed to redifferentiation we find them somewhat different.

It is evident that when a part such as the posterior end of Leptoplana is removed the region of the part remaining which immediately adjoins the eut surface must be most affected functionally. It is brought into conditions both external and internal resembling those to which the extreme terminal region of the part removed was subjected. If under the conditions of the experiment other portions of the old parts do not beeome the functional represcntative of the part removed this region may come to represent its extreme terminal portion. In many cases undoubtedly a small amount of new tissue is formed in comnection with the closure of the wound as a result of the presence of the wound and without relation to functional conditions in other parts. This I have designated the initiatory stage of regeneration (CHILv, '05b). This small region resulting from the local proliferation becomes the only functional representative of the part removed and this represents only its extreme terminal portion. In other cases the regions immediately adjoining may react to the altered conditions and so also become inrolved: in any case, however, the reaction does not extend far from the cut surface. Now redifferentiation or differentiation begins and is accompanied by localized proliferation, i. e., regencration, and the terminal portion of the part removed appears as what in commonly called new tissue:. But with the formation of a functional terminal region the conditions for the formation of the region next adjoining it are established and so on until last of all the basal region, $i$. e. that region of the part removed which adjoincd the cut surface is established and regeneration is qualitatively complete. Each portion of the new part thus formed is at first. relatively too small and continues to grow, i. e., to undergo functional hypertrophy until physiological equilibrium is attained.

The difference between this process and that of $»$ redifferentiation lies in the fact that in regeneration functional substitution occurs only in regions immediately adjoining the cut surface or in the small 
amount of new tissue formed as the result of conditions immediately connected with the presence of the wound. Hence the proliferation does not involve any large portion of the old parts but is localized in this region and in the parts arising from it. In other words redifferentiation is the result of altered functional conditions in a considerable portion of the old tissue while regeneration is the result of altered functional conditions localized in the region immediately adjoining the cut surface.

Regeneration may of course be qualitatively and quantitatively complete or incomplete according to conditions, e. g., the capacity of the tissues for growth, the relative functional activity of this region as compared with others, etc.

With this interpretation it becomes evident at once why the terminal portion of the part removed is formed first - a general rule in cases of regeneration. No other interpretation, so far as I am aware, has offered any adequate explanation of this extremely important fact. Indeed Houses' hypothesis ('04) proceeds on the assumption that the opposite occurs. But taking the planarians as an example it is sufficiently clear that the functional conditions at the cut surface after removal of a part are more like those previously existing in the terminal region of the part removed than those in any other region of that part.

The interpretation also corresponds closely to the facts of observation: in Leptoplana, for example, when we remove a posterior part there is no extensive functional substitution in the old part, but almost as soon as the wound has closed the very small terminal region begins to function like the tip of the tail, i. e., is used for attachment and in the manner characteristic of this region. None of the parts anterior to this, however, represent other regions of the tail. The establishment and functional growth of this new terminal region itself determines the functional conditions for the region next anterior to it and so on until the whole missing part is functionally present in the new tissue, though of small size.

This interpretation will serve, I believe, not only for Planaria but for regeneration in general. The conditions determining redifferentation in the one case and regeneration in the other are to be sought in the functional specification of the tissues and in the degree of change in conditions resulting from removal of a part: these two factors are, however, closely connected for it is evident that the greater the functional specification of a given region the greater 
the alteration in conditions consequent upon its removal and on the other hand the greater the functional specification of the part remaining the less likely it is to react by extensive redifferentiation.

The probability of the occurence of regeneration as opposed to redifferentiation increases therefore as functional specification of the tissues increases or in other words the greater the degree of differentiation - the risible result of functional specification -- the less likely is extensive functional substitution and consequent redifferentiation. This conclusion also corresponds to the facts. A headless piece of Bipclium, for example, behaves much more nearly like an uninjured animal than does a piece of Cestoplana from which the head has been removed just posterior to the ganglia (CmrLd, '05 b) and in Bipalizm the new head arises by redifferentiation, in Cestoplana by regeneration.

Replacement of parts in Planaria simplicissima is wholly or almost wholly the result of regeneration, while in $P$. maculata only the terminal portions are regenerated, the other parts being formed by functional substitution and redifferentiation of old parts. The fact indicates, according to the view suggested here, that the functional specification of parts is greater in $P$. simplicissima than in $P$. maculata. To demonstrate this difference in functional specification would require too much time here. I need only say that Morcas's experiments with the two species show that a difference does exist. The fact that pieces from the prepharyngeal region may give rise in both species to heads at both ends and pieces from regions near the posterior end to tails at both ends in $P$. simplicissima but not in I. maculata (Morian, '04a, '04 b) is an indication of the difference in functional specification. In short the posterior region in $P$. simplicissima is functionally more "tail-like s than the corresponding region of $P$. maculatu. I hope to consider the problem of axial heteromorphosis in Planarians and other forms more fully in another paper.

It follows also from this view of the problem that redifferentiation and regeneration are not fundamentally different. Redifferentiation as the term is used in this connection is simply the result of a functional change involving a considerable region of the old part while in regeneration the functional change is localized at or very near the cut surface. The first structural step in regeneration is then a redifferentiation or a differentiation of a small part of the old region.

But very often practically no regulation occurs beyond closure of the wound: we have now to consider the determining conditions in these cases. 


\section{c. Absence of Form-Regulation.}

In a large number of cases removal of a part is not followed by its replacement in any way. Removal of the anterior end in Cestoplana and Leptoplana by section at levels considerably posterior to the ganglia is an example of the absence of form regulation and in the higher animals the power of replacement of lost parts becomes more and more limited. This limitation is commonly regarded as the result of the specification or differentiation of the tissues to such an extent that they cannot react to the conditions consequent upon the removal of a part. While this view is undoubtedly correct for many cases, especially those in the rertebrates, yet it is insufficient to account for such cases as the failure to reproduce an anterior end in such forms as Cicstoplana and Leptoplana and many others. Here we know that the specification of the tissues is not such that it cunnot react to altered conditions for extensive proliferation and complete replacement of missing posterior parts oceurs at the sime levels at which replacement of anterior parts is impossible.

We are forced therefore to eonsider other factors in these cases. My observations on the close parallelism between the degrec of regulation and the character of the motor reactions in several forms as well as the similar observations of LILLIE ("O1) on Dendrocoelz'm afford a clue to the determining conditions in these cases. It is the degree of alteration in character and intensity of the functional conditions in the piece which is concerned here. When we remove the anterior end from Cestoplana or Leptoplana at any other level than that immediately posterior to the ganglia or from Dendrocoelum at levels posterior to the pharynx the functional conditions in the anterior region of the remaining piece are so far different from those which determine the formation and persistence of an anterior end that replacement does not take place; indeed after closure of the wound and the formation of a small anount of new tissue in the concavity no further growth occurs, simply because there are no stimuli of any kind in this region adequate to bring about extensive development. Here we have to do largely if not wholly with a quantitative reduction in intensity of the functional conditions, though it is often difficult to draw the line between quantitative and qualitative differences. Between this condition and that of complete regeneration all intermediate stages may occur in one species as I have shown for Leptoplane (CHILv, '04c) and Cestoplana (CHILd '05b). 
The remarkable parallelism in such cases between the motor phenomena and the power of regeneration in the piece is to my mind of the greatest importance as indicating the close relation between formregulation and functional conditions.

In forms where the tissues are capable of reacting to changes in functional conditions an alteration in the quality of the conditions at least within certain limits, must result merely in change in the character of the form-regulation. Here we have the factors involved in so-called changes in polarity and in heteromorphosis which will be discussed elsewhere. The absence of form-regulation at the anterior end in postganglionic regions in such forms as Leptoplana and Cestoplana is clearly due at least in large measure to quantitative reduction in the intensity of the functional conditions. To sum up: the failure to replace lost parts by any definite structure may be due either to absence of adequate conditions of any kind, to the presence of conditions of such a character qualitatively that reaction by replacement is impossille, or finally to a high functional specification of the tissues rendering them incapable of responding by replacement of the part to the conditions present.

\section{d. Mixed Form-Regulation.}

Thus far we have discussed the problem from the standpoint of the two prucesses regeneration and redifferentiation. It is evident from what has been said that there is no theoretical reason why regeneration and redifferentiation should not appear in various degree of combination. As a matter of fact regeneration is scarcely possible without some degree of redifferentiation involving regions other than those immediately concerned in the formation of the new part and redifferentiation is usually accomplished by at least some slight degree of regeneration: all who have worked in this field are familiar with such a combination. Indeed the distinction between regeneration and redifferentiation is artificial though convenient for practical purposes.

There are, however, certain cases in which the combination of regeneration and redifferentiation is very evident and these afford us the most suitable basis for discussion. Perhaps the most familiar as well as one of the best cases of this sort for purposes of illustration is that of Planaria maculata. The facts regarding this form have been reviewed above. Here only the terminal regions of the part remored are replaced by the formation of new tissuc, the other 
parts being formed as the result of more or less extensive redifferentiation in the old tissues. This and other similar cases are merely the result of incomplete functional substitution in the old part. The region of the old part involved becomes the functional representative of a portion - the basal portion of the part removed while the functional conditions characteristic of its extreme terminal region are localized at the cut surface. Proliferation occurs here in the characteristic manner, the tip of the new part being formed first and then the next portion, and so on until equilibrium is attained. I hope to show at a later date that even in Planaria maculata the relation between redifferentiation and regeneration varies to some extent at different levels of the body, and to give reasons for this difference. Whether in a given case redifferentiation or regeneration plays the greater part is merely a matter of detail.

\section{e. Other Processes of Form-Regulation.}

While it is not the present intention to discuss these exhaustively since such a discussion would be practically equal to a consideration of the factors concerned in the development of form, certain cases of apparently unusual character are mentioned briefly.

One of these, the case described by myself (CHLLd, '03b), where zooids and parts of zooids of Stcnostome attached to the anterior end of an older zooid undergo complete destruction and resorption is of some interest. In the paper describing this case the close relation of the process to the cephalic ganglia was established and the process was regarded as essentially functional in character, the older more active zooid undergoing functional hypertrophy at the expense of the younger zooids attached to it. Evidently position as well as age of the zooids is also inrolved, for the young zooids formed at the posterior end of an old zooid do not undergo such a resorption but increase even without food until equilibrium is attained. This relation is also functional in nature: a posterior zooid so long as in organic continuity with an older zooid in front of it is functionally a part of that zooid in many respects, and functional equilibrium is maintained as if no fission plane were present. An anterior zooid is not, however, a functional part of a zooid posterior to it, consequently if the latter gains the upper hand, i. e., if it becomes the dominant element functionally speaking, a regulation occurs in which the younger anterior zooid disappears completely.

Another somewhat unusual case is that of Clavellina, described 
by DrIEsch ('02), in which under certain conditions all visible differentiation disappears and from the apparently undifferentiated mass of cells a new complete individual arises. In this case the disappearance of the old structure does not differ from the degeneration of old parts which is frequently a prominent characteristic of redifferentiation: it is simply a reaction to altered conditions. Here, however, the mass does not lose the power of contiumed existence. As the result of the loss of specinication it comes to represent a "whole", this ehange being rather negative than positive. In this relatively undifferentiated whole the conditions for renewed development are probably not widely different from those existing in the embryo i. e., provided the mass actually does lose its specification to the extent that Driesch asserts. As yet noither Drrescn nor any one else has given us an exact account of what actually occur's here. This case presents no other obstacle to interpretation than do many other cases of regulation. Moreover, the fact that Clatellina as well as many other forms may underon form-regulation by several different methods is merely the result of difference in functional conditions in the different cases.

\section{f. The Localization of Structures in Form-Regulation.}

As is well known the observations of Driesch ('99) on the »localization of morphogenetic processes constituted the basis for his theory of the vautonomy of vital processes «. I believe that Driescu's conclusions follow logically from his premises, but his premises are based on what seems to me as well as to many others a total misconception of the character of the phenomena observed. According to the views expressed in the present paper the problem of the localization of structures is essentially the problem of the localization of functional conditions and this problem presents no insuperable obstacles to solution.

The present discussion of this problem is, however, confined chiefly to one typical case, viz. the position of the new pharynx in form-regulation in planarians. Cestoplena and Planaria maculata afford us the best illustrations. In both of these forms the position of the new pharynx varics according to the level of the body from which the pieces are taken. In the most anterior pieces the pharynx appears near the posterior end, and it approaches the middle as the level of the piece approaches the old pharyngeal region: in Cestoplana it is far anterior to the middle in all postpharyngen! Archiv f. Entwicklungsmechauik. Xx. 
pieces in which it appears; in Planaria maculata, however, its position in postpharyngeal pieces varies, but is never posterior to the middle. I have already discussed this question of pharyngeal position in connection with Cestoplana (CHILD, '05c) and refer to this discussion, considering only a few fundamental points here.

In the first place the position of the pharynx is determined by the localization of certain functional conditions. In the papers referred to evidence las been brought forward to support this point. Secondly, pieces from the prepharyngeal region behave differently from postpharyngeal pieces; in short they react in a manner more characteristic of the anterior region while postpharyngeal pieces behave more like postpharyngeal parts of the body. In each case the posterior region of these pieces is subjected in consequence of the operation to conditions approaching those characteristic of a postpharyngeal region and the anterior end to conditions characteristic of a prepharyngeal region. The posterior region of the prepharyngeal piece becomes functionally a postpharyngeal region and the anterior region of the postpharyngeal pice becomes functionally a prepharyngeal region. Now the portion of each piece involved in the change will depend largely' on the original functional specification of the tissues for that will determine in large measure the conditions to which the respective ends are subjected. In a piece from the region just behind the head prepharyngeal conditions are so far dominant that only a small posterior part can become functionally postpharyngeal. As we approach the region of the old pharynx prepharyngeal conditions become less intense and a larger part becomes functionally postpharyngeal. In postpharyngeal pieces on the other hand postpharyngeal conditions are so far dominant that the functional change is limited to the anterior region, in Cestoplana very small, in Planaria larger and variable according to level.

In typical uninjured specimens the pharynx is at or near the middle of the body. In these pieces undergoing regulation the region between the functionally prepharyngeal and the functionally postpharyngeal parts is the "functional middle " and it is here that the new pharyax always appears. I am inclined to believe that functional conditions connected with the intestine are chiefly responsible for the formation of the pharynx but this belief does not alter the case in any way. There is, moreover, in the motor reactions of the piece a visible indication that the functional changes are as described. Here then localization of a morphogenetic process is in one sense a simple matter. 
The position of the new pharynx in Planaria simplicissima posterior to the old part in prepharyngeal pieces and anterior to it in postpharyngeal pieces, which MORGAN finds so puzzling is thus readily understood.

The localization of growth in the regenerating tails of fishes (Morgan, '00c, '02) in regard to which Morg.tN advances his peculiar theory regarding tensions, which I confess I cannot grasp, is undoubtedly to be interpreted on a functional basis. The functional activity of a strongly forked tail is very different from that of a rounded tail as may readily be observed. In regenerating tails the growth is always most rapid where the functional conditions are most intense. If we rould induce the fish to alter the manner in which the tail functions or attempts to function after cutting off the tip, a tail of different form would regenerate.

These cases are, I think, sufficient to show that the problem of the localization of morphogenetic processes does not necessarily lead us to take refuge in vitalism. The psychological problem with which every theory must suoner or later reckon remains of course untouched. In short, though it may be possible at some future time to demonstrate the existence of a vitalistir or autonomistic factor in comnection with function, there is no ground for belief that we can aceomplish this directly with structure.

\section{g. The Relation between External and Internal Conditions.}

Changes in the general external conditions do not bring about specific form-regulation in most animals as they do in plants. Some of the lower attached forms, e. g., the hydroids, whose conditions of life are more or less similar to those of plants do however show such a reaction in greater or less degree. In the motile forms localized conditions, e. g. the conditions at the anterior and posterior ends of a moving piece of Planaria may play some role in determining the result though I am inclined to believe that they are comparatively unimportant, for in many eases these pieces of Planariat if left undisturbed show scarcely a trace of movement and may even become enveloped in slime until the new head and tail have appeared.

In any case, however, the external conditions are effective only as they bring about changes in the internal conditions: it is these latter which determine the result in the organism. 


\section{Critique and Conclusion.}

While it is beyond the purpose of this paper to enter into any extended criticism of other theories of regulation a brief discussion of one hypothesis which superficially at least resembles my own is necessary. I refor to a paper by HoLmes ('04), a most interesting contribution, but containing I believe certain inconsistencies which make the hypothesis suggested untenable.

Many of the ideas expressed in the general introductory discussion are similar to my own, the importance of function being emphasized. The conception of "social pressure «, i. e., the influence exercised on a cell by its fellows, as the determining factor in differentiation is developed. In these respects his hypothesis is based on the same general principles as my own, though differences of detail exist. Hounes' analysis of the relation be-

Fig. 63.

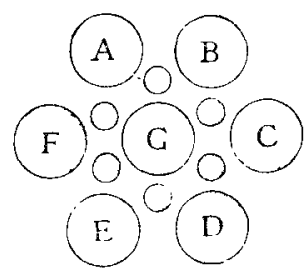
tween the cells is, however, widely different from mine.

Holules takes as starting point the assumption that the orgauism is a symbiotic community and self-regulating. He defines form-regulation »as an expression of the effort to attain a condition of functional balance* (p. 277). This definition is somewhat similar to my own conception of the process, though

I should avoid the use of the word seffort $*$. The cases of symbiosis between the hydra and alga and between the fungus and alga in a lichen are discussed as examples of self-regulation in symbiotic communities. These cases are scarcely pertinent to the matter in hand becanse the regulation here is merely quantitative not qualitative. But even if we proceed on the basis that the organism is a symbiotic community, accepting HoLmes' premises, I believe we cannot logically reach his conclusions.

As an illustration of his theory he gives a diagram which I have reproduced (Fig. 63) and discusses it as follows: "Let us imagine an organism made up of a number of differentiated cells, each of which derives some advantage from some substances produced by the contiguous cells, and giving out some substance upon which the contiguous cells are more or less dependent. We will suppose that in addition to these differentiated cells, there are scattered through the body numerous indifferent or embryonic cells whose multiplication 
is held in check by the others but which upon the removal of any part respond to the functional disturbance by growth and multiplication near the place of mutilation. We may represent our hypothetical organism graphically. by the following diagram in which the differentiated cells are represented by the larger circles $A, B, C$, etc., and the indifferent cells by the smaller circles between them. Each cell such as $A$ contributes something utilized by $B, G$, and $F$, and derives somcthing in return from each of these sources. Now snppose $A$ is remored; the indifferent cell lying near by, no longer held in check by the same stimuli as before, begins to grow and develop. What line of differentiation will it most naturally take? Owing to the symbiotic relation subsisting between the cells differentiation in the direction of $A$ will be most favored as this secures the advantages which $A$ received. In other words this will be the direction of development along which social pressure will tend to guide it. And the result will be a regeneration of the missing part « (p. 282).

It seems to me that this is exactly what will not occur under these conditions. If all the cells $A-F$ are symbiotically correlatel then removal of one of them, $A$, must affect all the others, $i$. e., the whole complex is altered by removal of one of its members. It is perfectly clear that the social pressures of the altered complex will not be in the direction of differentiation of the indifierent cell into something like $A$ but in some other direction, in other words the iudifferent cell cannot replace $A$ but will form something different. Moreover, since all the cells were dependent upon $A$ in some degree the removal of $A$ will probably render continued existcnce impossible for some of them and their place will be taken by the undifferentiated cells but these will also develop into something different because the "social pressure is altered. It is perfectly evident that no regulation in the sense of replacement of a missing part could occur in such a complex.

The diagrams may, however, be used for strictly quantitative processes. If we suppose that $A-F$ represent a series of organs symbiotically dependent and we remove a half of one of them, $A$ for example, then the "social pressure " may conceivably bring about hypertrophy by development of undifferentiated cells in the half of $A$ remaining. But even here there is no certainty that the reduction of $A$ may not alter the other elements of the complex to such an extent that the social pressure will be different.

Moreover, the assumption that the differentiated cells hold the 
indifferent cells in check seems to me wholly gratuitous. It is difficult to understand on a functional basis why these cells should be there if they are constantly subjected to inhibitory conditions so long as the organism is uninjured. If they are present their presence in different forms must be due simply to the absence of adequate stimuli to further development, but their existence must just as certainly be the result of positive not negative conditions.

Fig. 64 .

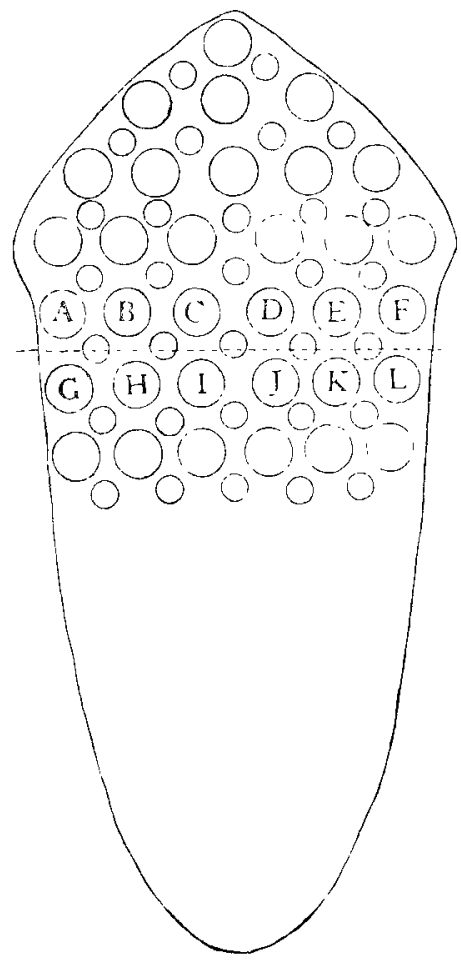

Fig. 65 .

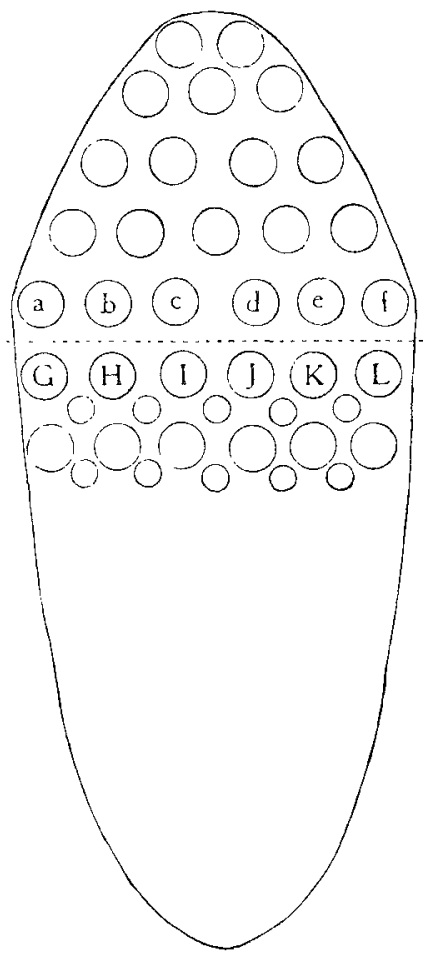

The most essential condition of all as I conceive it for the replacement of a lost part is that the removal of the part shall leave the essential functional conditions of the complex which concern the part much the same as before: as $I$ have shown in the preceding section alteration of these conditions beyond a certain limit makes replacement impossible. To return to HoLmes' diagram, replacement of $A$ can occur only when the relation is largely one sided, i. e., when $A$ is dependent on $B-F$, but these latter are not to any marked 
degree dependent on $A$. In this case and in this case only will the "social pressure " force the undifferentiated cell to differentiate into something like $A$.

As I have said above, HoLnes' hypothesis will serve us only for quantitative not for qualitative conditions. The symbiotic selfregulation from which he starts is quantitative not qualitative: regttlation in self-regulating machines to which he also refers is likewise quantitative. In the paragraph following that quoted above Hocmes attempts a more specific application of the hypthesis. The two diagrams to which he refers are reproduced here as Figures 64 and 65. The discussion is as follows: "We will now attempt to apply our theory to the regeneration of a more complicated organism such as a planarian. When the head of a planarian is cut off the anterior end of the body, as is well known, begins to regenerate a new head. The process is one of extreme complexity, but may be interpreted according to the principle that we have just applied. For the sake of illustration we will suppose that regeneration is effected by the development of new tissue in front of the cut and its transformation into the missing part. - In the diagram the differentiated cells are represented by eireles containing letters, the indifferent cells being indicated as before by circles of smaller size. We will suppose the body cut across in the position of the dotted line (Fig. 64 of present paper). The indifferent cells behind the cut being subjected to new conditions of stimulation owing to the functional disturbance set up grow and multiply, producing a mass of tissue at the anterior end of the body, as is shown in Figure 3 (Fig. 65 of present paper). This mass of cells is differentiated into a new head through the influence of the posterior piece. How is this transformation effected? We may assume that each of these cells is totipotent - capable of developing into any kind of cell of the body of the animal. The line of development a cell of this mass takes is a function of its social pressure. Let us consider the cell $d$ which occupies the same position in relation to the cells $I, J, K$ as was occupied by the cell $D$ in the entire animal. The cell $D$, ex hypothesi, was in a position of simbiotic relationship with these cells. It will therefore tend to differentiate in the direction of $D$. In the same way the new cell will tend to differentiate by virtue of its social pressure into a cell like $E$, and so on, the row of new cells just in front of the older cells behind the cut end differentiating by virtue of their environment in the same way as their predecessors. The next row in. 
front of these will then be under the same necessity of differentiating into cells. like those which occupied the same situation in the entire animal. As soon as the cells are started to develop in a certain way by virtne of the social pressure of the cells behind them they begin to exert a social pressure upon the cells in front, and those in turn will exercise directive influence upon the next anterior series, and so on. The process will go on until the new cells are worked orer into the form of the missing anterior end. When this has been effected there is a functional equilibrium attained which inhibits further development (p. 282-284).

As a matter of fact not only in planarians but in other forms as well differentiation occurs in the opposite dircction. Moreover, differentiation of the tip of the new part may be far advanced before the base has even been formed. This is the case in Plomerin simplicissima and in Leptopland (Figs. 47-50). The new tissue formed first develops into the terminal portion of the regenerating part. This iact has been so often stated and is so well establisher that every hypothesis of rogulation mnst take it into aceount.

Moreover, in this attempted explanation Hocmus tacitly throws over his symbiotic hypothesis, for he issumes that only the cell, behind those which are differentiating have any effect on them. According to his own premises the rcmoval of the head ought to bring about profound changes in the social pressure in the old parts, yet he assumes that it does not and that conditions in the old part remain unaltered so far as those affecting the head region are concerned. According to my conception it is quite necessary that these conditions do remain essentially maltered, but according to Holnies' bypothesis of symbiotic relations they cannot. In short when an attempt is made to apply Hownes' theory it is evident that a onesided relation, not a symbiotic relation is necessary for the replacement of a particular part.

In HoLses' discussion of heteromorphosis and morphallaxis certain points also require criticism bot since these are less fundamental discussion is postponed.

It is, I think, sufficiently demonstrated that in the first place Hownes' conclusions do not follow from his premises and secondly that his conception of regeneration at least does not accord with the facts. In a strictly symbiotic organism regulation must be either merely quantitative or else must involve a change in all parts and the establishment of a new equilibrium different from the old, i. e., 
the formation of an organism differing qualitatively in both new and old parts from the original. Confusion on this point is largely responsible for the point of view adopted in his paper.

Perhaps it is due both Holmes and myself to state that the idea common to both of regulation as functional equilibration was developed in entire independence of each other. The essential features of the hypothesis advanced in the present paper were formulated and partial statements were in print or in press at the time HoLmes' paper appeared. The difference in our ideas of the method by which functional equilibration occurs are probably sufficient evidence of independence.

In certain papers which have only recently come to my notice the botanist KLems ('03, '()t) has stated conelusions very similar to those expressed in my Studies on Regulation and in the present paper. In plants however, the general external conditions exercise a much more important and direct influence in altering internal conditions than in most animals. Certain simple sessile animals, however, e. gr., the hydroids, approach the plants in these respects.

The fact that independent workers in different fields are reaching similar conclusions with regard to regulatory phenomena possesses a certain significance as indicating a real advance.

In conclusion I desire to suggest a definition of regulation which justifics the retention of the word, to which objection is often made in conserucnce of the special meaning with which Disiescir has invested it. This definition does not differ greatly from that of HoLnes althongh our ideas are quite different:

Regulation eonsists in the return or approach to physiological or functional equilibrium after such equilibrium has been disturbed.

It is clear that according to this definition the phenomena usually included under the head of form-regulation are merely special cases of regulation in general. In these particular cases functional conditions are such that great changes in structure follow the disturbance of equilibrium. Moreover, regulation may occur without the replacement of a missing part or the formation of any other part in its place: It is well known that removal of a leg in animals where regeneration does not occur is followed by extensive regulation in various portions of the complex remaining. A satisfactory definition of regulation must include such cases as well as those in which the part is replaced, 
I believe with HoLmes that the life of an organism is a continuous series of regulations; some of these are accompanied by extensive alterations of structure and form, others are not, according to conditions involved.

According to this view also the phenomena of regeneration, redifferentiation, etc. are not phenomena sui generis but are simply special manifestations of the power of growth and development existing in organisms, their special form depending upon certain special conditions.

I hope in later papers to develop these ideas further and to apply them to other cases of regulation.

\section{Summary.}

A complete and consistent summary of the paper is scarcely possible since the paper is in itself in a sense a summary. The following are, however, the most important points.

1) Regulation may be defined as consisting in the return or approach to physiological or functional equilibrium after such equilibrium has been disturbed.

2) The planarians serve as an excellent basis for the consideration of the problem of form-regulation since they exhibit various processes and degrees of form-regulation combined in various ways. Moreover, in these forms we have in many cases in the motor reactions of pieces and the relation between form-regulation and the nervous system, a clue to the character of the ehanges in functional conditions resulting from section and their localization.

3) The processes distinguished more or less artificially as redifferentiation and regeneration can be interpreted on a functional basis and it is possible to distinguish more or less exactly the conditions which determine the occurrence of one or the other.

4) Other processes of form-regulation are like these merely special cases and must be investigated as such.

5) Replacement of a lost part can occur only when the functional complex remaining retains the essential conditions of the whole so far as this part is concerned. Alteration of the functional complex beyond a certain limit leads to the establishment of a new equilibrium which may be accompanied by complete reorganization, heteromorphosis, or partial or total failure to replace the part removed. 


\section{Zusammenfassung,}

Eine vollstïndige und scharfe Zusammenfassung der Abhandlung zu geben ist kaum möglich, weil die Abhandlung in sich selbst in gewissem Sinne eine Zusammenfassung darstellt. Die wichtigsten Punkte jedoch sind die folgenden:

1) Regulation kann definiert werden als Rïekkehr zum physiologischen oder funktionellen Gleichgewicht oder Annäherung an dasselbe, nachdem dieses Gleichgewicht gestürt worden ist.

2) Die Planarien dienen zu einer vorzüglichen Grundlage für die Betrachtung des Formregulationsproblems, weil sie verschiedene Prozesse und Grade der Formregulation in mannigfacher Weiso kombiniert darbieten. Überdies haben wir bei diesen Formen in vielen Fillen an den Bewegungsreaktionen der Stïcke und an den Beziehungen zwischen Formregulation und Nervensystem einen Schlïssel zum Verständnis des Charakters der Veränderungen in den funktionellen Bedingungen, die von der Schnittfihrung and ihrer Lokalisation herrïhren.

3) Die Prozesse, die mehr oder weniger künstlich als Redifferenzierung und Regeneration unterschieden werden, künnen auf einer frnktionellen Grundlage ausgedeutet werden, nnd os ist müglich, mehr oder weniger genan die Bedingungen, welche das Vorkommen des Einen oder Andern bestimmen, zu unterscheiden.

4) Andre Prozesse der Formregulation sind gleich diesen rein speziclle Fïlle und mïissen als solche untersucht werden.

5) Wiederersatz eines verloren gegangenen Teils tritt nur ein, wenn der zurickbleibende funktionelle Komplex die Hauptbedingungen des Fanzen in bezug auf diesen Teil behïlt. Störungen des funktionellen Komplexes iiber eine gewisso Grenze hinaus führt zur Aufstellung eines nenen Gleichgewichtes, welches von einer vollstiindigen NeugestaItung, Ileteromorphosis, oder völligem Fehlschlagen der Ersatzbildung eines entfernten Teils begleitet sein kann.

\section{Bibliography.}

Bunnen, C. R., '01. On the Plysiology of the Planaria maculata with especial Reference to the Phenomena of Regeneration. Amer. Jnum. Physiol. Vol. Y. No. 1. 1901.

_02. Embryonic and Regenerative Dovelopment in Planarians. Biol. Bull. Vol. III. No. 6. 1902.

03. Pactors in Heteromorphosis in Planarians. Archiv f. Entw--Mech. Bd. XVI. II. 1. 1903.

Chuld, C. M., '02. Studies ou Regulation. I. Fission and Regulation in Stenostoma. I'ts. I, II and III. Archiv f. Entw.-Mech. Bd. XV. H. 2 1. 3. 1902. '03a. Studies on Regulation. II. Experimental Control of Form-Regulation in Stenostoma. Archiv f. Entw.-Mech. Bd. XV. H. 4. 1903.

'03b. Studies on Regulation. III. Regulative Destruction in Zooids and Parts of Zooids in Stenostoma. Archiv f. Entw.-Mech. Bd. XVII. II. 1. 1903.

- 04 a. Studies on Regulation. IV. Some Experimental Modifications of Form Regnlation in Leptoplana. Journ. Exper. Zool. Vol. I. No. 1. 1904. 
Child, C. M., '04b. Studies on Regulation. V. The Relation between the Central Nervous System and Regeneration in Leptoplana: Posterior Regeneration. Journ. of Exp. Zool. Vol. I. No. 3. 1904.

— '04c. Studies on Regulation. VI. The Relation between the Central Nervous System and Regulation in Leptoplana: Anterior and Lateral Regeneration. Journ. of Exp. Zool. Vol. I. No. 4. 1904.

—_ '05a. Studies on Regulation. VII. Further Experiments on Form-Regulation in Leptoplana. Journ. of Exp. Zool. Vol. II. No. 2. 1905.

'05b. Studies on Regulation. VIII. Functional Regulation and Regenera. tion in Cestoplana. Archiv f. Entw.-Mech. Bd. XIX. H. 3. 1905.

'05c. Studies on Regulation. IX. The Position and Proportions of Parts during Regulation in Cestoplana in the Presence of the Cephalic Ganglia. Archiv f. Entw.-Mech. Bd. XX, H. 1. 1905.

- '05d. Studies on Regulation. X. The Positions and Proportions of Parts during Regulation in Cestoplana in the Absence of the Cephalic Ganglia. Archiv f. Entw.-Mech. Bd. XX. H. 2.

Driesch, H., '99. Die Lokalisation morphogenetischer Vorgänge. Ein Beweis vitalistischen Geschehens. Archiv f. Entw.-Mech. Bd. VIII. 1899.

- '01. Die organischen Regulationen. 1901.

'02. Studien iber das Regulationsvermögen der Organismen. 6. Die Rcstitutionen von Clavellina lepadiformis. Archiv f. Entw.-Nech. Bd. XIV. H. 1 u. 2. 1902.

Hownes, S. J., '04. The Problem of Form-Regulation. Archiv f. Entw.-Mech. Bd. XVII. H. 2 u. 3.1904.

KLebs, G., 03 . Wilkürliche Eutwicklungsïnderungen bei Pflanzen. Jena 1903 . '04. Über Probleme der Entwicklung. Biol. Centralbl. Bd. XXIV. Nos. 14 -19. 1904.

Lillie, F. R., '01. Notes on Regeneration and Regulation in Planarians (continued). American Journal of Physiology. Vol. VI. No. 2. 1901.

Murgan, I. H., '98. Experimental Studies of the Regeneration of Planaria maculata. Archiv f. Entw.-Mech. Bd. VIII. 1898.

'00a. Regeneration in Bipalium. Archiv f. Entw.-Mech. Bd. IX. 1900.

'00b. Regeneration in Planarians. Archiv f. Entw.-Mech. Bd. X. 1300.

'00c. Regeneration in Teleosts. Archiv f. Entw.-Mech. Br. X. 1900.

'01a. Frowth and Regenoration in Planaria lugubris. Archiy f. Entw.Mech. Bd. XIII. 1901.

'01 b. Regeneration. New York 1901.

'02. Further Experiments on the Regeneration of the Tail of Fishes Archiv f. Entw.-Mech. Bd. XIV. 1902.

'04 a. The Control of Heteromorphosis in Planaria macnlata. Archiv $f$. Entw.-Nech. Bd. XVIr. 1904.

'04b. Regeneration of Heteromorphic Tails in Posterior Pieces of Planaria simplicissima. Journ. of Exp. Zool. Vol. I. No. 3. 1904. 